\title{
Structure-function relationships in the mineralocorticoid receptor
}

\author{
Jyotsna B Pippal and Peter J Fuller \\ Steroid Receptor Biology Laboratory, Prince Henry's Institute of Medical Research, PO Box 5152, Clayton, Victoria 3168, Australia \\ (Correspondence should be addressed to P J Fuller; Email: peter.fuller@princehenrys.org)
}

\begin{abstract}
The signature action of aldosterone in the regulation of electrolyte and fluid balance is well established. However, the role of aldosterone as an important contributor to morbidity and mortality in heart failure has gained a heightened interest in recent years, but the mechanisms of this action are not well understood. Aldosterone is the principal physiological ligand for the mineralocorticoid receptor (MR), a ligand-activated transcription factor, that also binds to the physiological glucocorticoid, cortisol. Both classes of hormones bind with similar affinity to the MR, but the molecular basis of selective and tissue-specific effects of MR ligands is not yet fully documented. The structural and functional determinants of MR function are described and their significance is discussed.
\end{abstract}

Journal of Molecular Endocrinology (2008) 41, 405-413

\section{Introduction}

The principal physiological mineralocorticoid hormone, aldosterone, plays a pivotal role in regulation of fluid and electrolyte balance in the kidney, salivary glands, sweat glands and colon (Arai et al. 1994, Farman \& RafestinOblin 2001). Classically, aldosterone is synthesized in the adrenal zona glomerulosa (Connell et al. 2008); however, emerging studies suggest that tissues other than adrenal cortex may also be capable of biosynthesis of aldosterone such as the cardiovascular (Takeda et al. 2000, Struthers 2004, Cachofeiro et al. 2008) and the central nervous systems (CNS; Connell et al. 2008). Aldosterone mediates its effects by acting through a ligand-activated transcription factor, the mineralocorticoid receptor (MR or NR3C2; Arriza et al. 1987). The MR is a member of the steroid/thyroid hormone receptor superfamily of ligandinducible transcription factors. Other NR in this family include the glucocorticoid (GR or NR3C1; Weinberger et al. 1985), thyroid (THRA, THRB; Benbrook \& Pfahl 1987), retinoic acid (RARA, B, C; Petkovich et al. 1987, Benbrook et al. 1988, Krust et al. 1989) and vitamin D receptors (VDR; McDonnell et al. 1987, Baker et al. 1988) as well as numerous orphan receptors for which, in most cases, no ligands are known.

MR is unique among the steroid receptors in being a physiologically important receptor for two classes of hormone, the mineralocorticoids, aldosterone and deoxycorticosterone (DOC) and the glucocorticoids, cortisol (in humans) and corticosterone (in rodents). Glucocorticoids also elicit their biological effects through the GR. The initial cloning of the MR revealed that its sequence is highly homologous to that of the GR (Arriza et al. 1987); the human GR and MR are $\sim 56 \%$ identical in the steroid-binding domain. Moreover, steroid-binding studies with the MR revealed that cortisol and aldosterone have a similar high affinity for the MR (Arriza et al. 1987, Rupprecht et al. 1993).

Polarized epithelial tissues, such as the colon and distal nephron, are considered to be classical targets of aldosterone. MR expression and function also extend to non-epithelial cells such as hippocampal and hypothalamic neurons, cardiomyocytes, the vasculature and adipocytes, with studies reporting both physiological and pathophysiological roles of MR at these sites (De Kloet et al. 1998). In recent years, the mechanisms of action of mineralocorticoids and glucocorticoids have been an area of extensive study in the face of the apparent paradox that despite acting through very closely related receptors and a common DNA response element, these hormones exert significantly diverse physiological effects in a tissue-specific manner. Some insights are provided by the consideration of the evolution of the corticosteroid receptor. Recent studies have identified an ancestral precursor to the vertebrate GR and MR. This ancestral corticosteroid receptor exhibits MR-like sensitivity to aldosterone and cortisol, indicating that the specificity for cortisol binding in the 
GR is evolutionarily derived. The sensitivity of the ancestral receptor to aldosterone, considering that aldosterone evolved in the tetrapods tens of millions of years after the appearance of the ancestral receptor, has been interpreted as reflecting a role for this receptor in responding to DOC (Ortlund et al. 2007).

Glucocorticoid concentrations are 1000-fold higher in plasma compared with aldosterone and thus, in principle, would be expected to preferentially occupy the MR. However, in the classical epithelial target tissues, preferential binding of aldosterone by the MR is ensured by 11ß-hydroxysteroid dehydrogenase type 2 (11ßHSD2, which metabolizes cortisol or corticosterone into inactive metabolites that are unable to bind MR and/or GR (Fig. 1). Studies in both rodents and humans show that $11 \beta$ HSD2 activity is essential for preventing mineralocorticoid activity of cortisol in that deficiency or inhibition of this enzyme results in the activation of MRs by glucocorticoids (Stewart \& Mason 1995, Ferrari et al. 2000). This in turn causes sodium retention leading to hypertension and renal dysfunction (White et al. 1997). In tissues such as the heart and selected areas in the CNS, the MR is unprotected by $11 \beta \mathrm{HSD} 2$ so that in these cells cortisol has access to the MR. Cortisol can act as an MR agonist in the kidney and colon, whereas in the heart and certain regions in the CNS, cortisol acts as an MR antagonist. The molecular basis of this ligand- and tissue-specific dichotomy is not yet understood.

Recently, several studies have provided evidence that not all biological effects of aldosterone are mediated through the MR by direct control of gene expression. Rapid, non-genomic effects of aldosterone have been shown in a variety of tissues (Wehling et al. 1992). In some cases, this appears to be the result of a crosstalk with other signalling cascades, such as activation by Src kinase of the epidermal growth factor receptor with consequent downstream signalling through the MAP-kinase pathway (Grossmann et al. 2008). Non-genomic actions also involve a number of other different signalling pathways including protein kinase C-, PIS-kinase and activation of transporters and pumps including the sodium hydrogen exchanger (NHE) and the Na-K-2Cl-cotransporter (Mihailidou et al. 2004, Grossmann \& Gekle 2007). Although it has been postulated that the effects may be mediated by a novel aldosterone receptor, there is no compelling evidence for this, the observed effects appear to be mediated by the classical MR (Funder 2006).

This review focuses on the recent findings on the structural and functional aspects of the MR.

\section{Mineralocorticoid receptor structure}

The human MRgene has been mapped to chromosome 4 in the q31.1-q31.2 region (Fan et al. 1989, Morrison et al. 1990). The $M R$ gene spans over $\sim 450$ kilobases and is composed of 10 exons of which 8 encode the fulllength 984 amino acid MR protein (Morrison et al. 1990). The two $5^{\prime}$ untranslated exons, referred to as $\mathrm{hMR} \alpha$ and $\mathrm{hMR} \beta$, splice to a common translated region; the expression of these mRNA species is therefore controlled by two distinct promoters (Zennaro et al. 1995). By contrast, the rat MR has three $5^{\prime}$ untranslated exons referred to as $1 \alpha, 1 \beta$ and $1 \gamma$. The mouse MR shares a similar genomic organization with the rat MR gene (Kwak et al. 1993).

The MR has a similar modular structure to the other members of the nuclear receptor superfamily with four structurally distinct sections or domains: the amino terminal domain (NTD), followed by a central DNAbinding domain (DBD), the hinge region and the C-terminal ligand-binding domain (LBD; Mangelsdorf et al. 1995). The NTD is encoded by exon 2 and contains activation function-1 (AF-1), a region which mediates ligand-independent interactions of the receptor with other nuclear proteins that initiate target gene transcription. Exons 3 and 4 encode the DBD, which contains two zinc fingers that interact with specific hormone response elements in the promoter regions of MR target genes. The last five exons encode the LBD, which, in addition to binding ligand, contains a ligand-dependent activation function-2 (AF-2; Viengchareun et al. 2007).

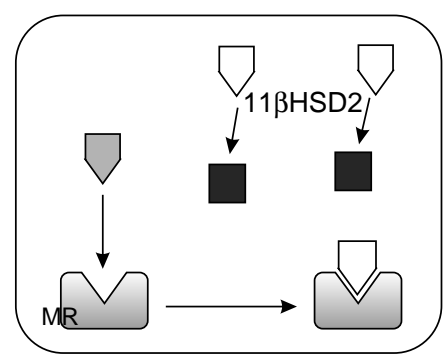

Epithelial cells

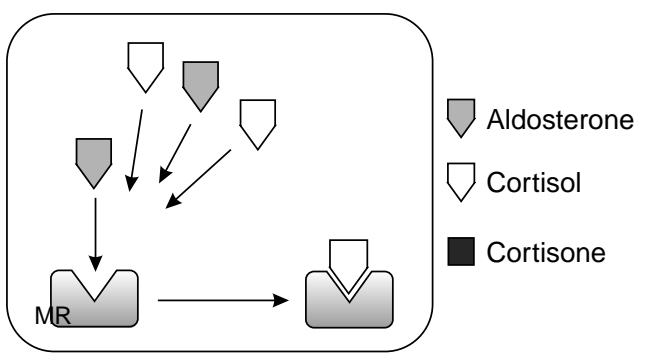

Non-epithelial cells

Figure 1 Schematic of protective mechanism of $11 \beta$-hydroxysteroid dehydrogenase 2 (11 $\beta$ HSD2) in epithelial versus non-epithelial cells: in the epithelial cells, $11 \beta \mathrm{HSD} 2$ prevents mineralocorticoid receptor (MR) from binding to cortisol by converting it to cortisone. In the non-epithelial cells, $11 \beta \mathrm{HSD} 2$ protection for MR is absent. 


\section{MR N-terminus}

The N-terminal domain is hypervariable both in size and length being the least conserved domain of all the NRs (Agarwal \& Mirshahi 1999). The MR has the longest NTD (604 amino acids) among all the steroid receptors; it represents half of the MR protein. This domain is very distinct from the NTDs of other steroid receptors, sharing less than $15 \%$ homology with the closely related GR, androgen receptor (AR) and progesterone receptor (PR). The N-terminus is, however, highly conserved among MRs of all mammalian species (Pascual-Le Tallec \& Lombes 2005) with $\sim 85 \%$ amino acid homology. NRs have a constitutive, ligand-independent transactivation function-1 (AF-1) in the NTD, which is important for interactions with the transcriptional coregulators and for intramolecular interactions with the LBD. However, the interacting surfaces in the MR-NTD have not been identified.

Functional mapping studies of the N-terminal AF-1 domain in the hMR identified amino acids 328-382, in the middle of the MR-NTD, as being important for transactivation function (Govindan \& Warriar 1998). However, a more recent study found that the MR $\mathrm{N}$-terminal region encompasses two distinct ligandindependent activation functions referred to as AF-1a and AF-1b which mapped to amino acids 1-167 and 445602 respectively (Pascual-Le Tallec \& Lombes 2005). A similar organization of the NTD was also reported for the rat MR (Fuse et al. 2000). A central inhibitory region (amino acids 163-437) has also been characterized, which robustly reduces AF-1a or AF-1b directed transcriptional activity. The mapping of AF- $1 \mathrm{a}$ and $\mathrm{AF}-1 \mathrm{~b}$ as distinct regions of the protein suggests a cell and/or promoter selectivity of the MR-NTD transactivation function. Significantly, these three regions of the MR-NTD also display a high degree of amino acid conservation between the mammalian MR sequences and a number of fish species (Oncorhynchus mykiss and Danio rerio) with amino acids 1-170 (AF-1a) of the human MR sharing 25\% identity; amino acids 244-300, 54\% identity, and amino acids 459-566, including AF-1b sharing 46\% identity with the two fish MR-NTDs (Lavery \& McEwan 2005, Baker et al. 2007). Furthermore, a ligand-induced, functional synergism between the AF-1 and AF-2 has been demonstrated in many nuclear receptors, supporting the concept that AF-1 significantly contributes to the ligand-induced transcriptional activity of nuclear receptors. Recently, McEwan et al. (2007) have developed the concept that the $\mathrm{N}$-terminus contains significant levels of naturally disordered structure which provides structural flexibility allowing multiple protein-protein interaction with the cellular transcriptional machinery.

The MR-NTD also contains four sumoylation or 'synergy consensus motifs' at positions K89, K399, K428 and K494 in the human MR. These sites are highly conserved in the MR across the species (Zennaro et al. 1995). Recent studies have suggested that these regions might play a role in interactions at multimer response elements (Iniguez-Lluhi \& Pearce 2000, Pascual-Le Tallec \& Lombes 2005). These different regions of the NTD are responsible for modulating the transcriptional activity of $\mathrm{MR}$ in a highly selective manner and are therefore key determinants of mineralocorticoid selectivity. To date, the crystal structure of MR-NTD has not been determined, a consequence presumably of its naturally disordered structure. The work of McEwan et al. (2007) would predict that a crystal structure will be derived only when it is associated with a binding partner.

\section{MR DNA-binding domain}

The centrally located DBD of 66 amino acids has the most highly conserved amino acid sequence among the members of the steroid receptor superfamily. It is characterized by eight conserved cysteine residues that coordinate two zinc atoms to stabilize the 'zinc fingers'. Crystallographic studies of the GR-DBD complexed with DNA demonstrate that the DBD folds to adopt a globular conformation consisting of two perpendicular $\alpha$-helices; residues important for DNA recognition and binding form part of the recognition helix. This domain also contains segments that are involved in receptor homo- and heterodimerization (Luisi et al. 1991). The steroid receptor subfamily, consisting of the AR, GR, MR and PR, binds to the half-site sequence AGAACA, whereas the oestrogen receptor (ER) recognizes the sequence AGGTCA. The DBD of MR is highly homologous with that of GR, sharing 94\% identity across the 66 amino acid DNA-binding domain. Accordingly, the glucocorticoid response element (GRE) is considered to also function as a mineralocorticoid response element (MRE; Arriza et al. 1987). Putative MREs, which have not already been characterized as GREs, have yet to be described.

\section{MR ligand-binding domain}

The MR LBD is a complex and multifunctional domain composed of 251 amino acids, sharing $~ 55 \%$ homology with the AR, PR and GR and $~ 85 \%$ homology across species (Sturm et al. 2005). The MR LBD crystal structure has recently been determined (Bledsoe et al. 2002, Fagart et al. 2005, Li et al. 2005); it exhibits remarkable structural similarity to the crystal structures of GR, AR, PR and ER (Shiau et al. 1998, Williams \& Sigler 1998, Matias et al. 2000, Bledsoe et al. 2002). It consists of $11 \alpha$-helices in 3 anti-parallel layers. The helices are numbered 1-12 according to the nomenclature originally used for the human retinoid receptors and the rat THRA; the region 
between helices 1 and 3 is unstructured in the MR, GR, AR and PR. This region, despite lacking a highly structured conformation and having no role in forming the ligandbinding pocket, does have a significant role in ligandbinding sensitivity in GR (Fuller et al. 2004). Helices 3, 4 and 12 are integral to ligand binding. A glutamic acid residue in helix 12 and a lysine residue in helix 3 , together with a hydrophobic pocket on the surface of the LBD composed of residues from helices 3, 4 and 5, are important for protein-protein interactions in that they form the AF-2 region. Although the crystal structure of the unliganded receptor has not been published, studies with other nuclear receptors suggest that helix 12 will be randomly distributed in the unbound conformation (Gronemeyer et al. 2004). Ligand binding induces a compact packing of the helices, allowing helix 12 to adopt a position where it interacts with helices 3,5 and 11 to form the hydrophobic groove on the surface of the LBD which represents AF-2. This groove interacts with coactivators containing an LxxLL motif (Bledsoe $e t$ al. 2005, Li et al. 2005). When compared with the other steroid receptors, the MR AF-2 is a powerful activator.

The specific residues within the ligand-binding pocket that interact with ligand have been extensively characterized (Geller et al. 2000, Rafestin-Oblin et al. 2003, Bledsoe et al. 2005, Li et al. 2005). In addition, the determinants and the nature of the interaction of antagonists with the LBD have also been determined. However, the antagonist conformation has not been solved. The determinants of specificity and selectivity for the receptors in this highly conserved structure are complex and diverse.

\section{MR ligand-binding specificity}

MR and GR share considerable structural and functional homology (Fig. 2), which is exemplified by the ability of glucocorticoids to bind both receptors. The glucocorticoids, cortisol and corticosterone bind to the MR with a similar affinity to aldosterone, yet aldosterone binds to the GR only at very high, nonphysiological concentrations. To understand the struc- tural basis of the specificity of aldosterone binding to the MR, Rogerson et al. (1999) created a series of chimeras between the LBD of the MR and the GR. The studies identified that the binding specificity of aldosterone for the MR is conferred by amino acids 820-844 in the human MR LBD. Of these 25 amino acids, 12 were identified as essential for aldosterone selectivity. This same region was also identified as critical for cortisol-induced transactivation but not for binding. Evidence from the crystal structures of the MR LBD (Bledsoe et al. 2005, Fagart et al. 2005, Li et al. 2005) suggests that amino acids 820-844 do not form part of the ligand-binding pocket indicating that aldosterone-binding specificity is determined by indirect interactions of these amino acids rather than a direct interaction with the steroid. Studies with the GR, PR and AR (Vivat et al. 1997, Robin-Jagerschmidt et al. 2000) involving AR:PR and PR:GR chimeras also point to the critical role of this region in determining the specificity of steroid binding and transactivation. The mechanism by which this region so profoundly influences steroid binding and its functional consequences remains to be fully determined.

Helices 3 and 5 act as a molecular switch, which regulates the specificity and sensitivity of steroid hormone receptors. Mineralocorticoid specificity in MR is thought to be provided partially by a hydrogen bond between asparagine- 770 on helix 3 and the $\mathrm{C}_{21^{-}}$ $\mathrm{OH}$ group of the ligand (Zhang et al. 2006). Geller et al. (2000) identified a point mutation in the human MR, serine at 810 to leucine $(\mathrm{S} 810 \mathrm{~L})$ in helix 5 , which causes exacerbated hypertension during pregnancy. The mutation results in altered specificity of MR allowing progesterone to function as an MR agonist instead of being an antagonist and for the receptor inactive product of $11 \beta \mathrm{HSD} 2$, corticosterone to both bind and transactivate the MR (Rafestin- Oblin et al. 2003). S810L lies just outside the critical region that confers mineralocorticoid-binding specificity to the MR. In the GR, the equivalent residue at the same position is methionine, which when substituted in the MR still retains the ability of aldosterone to transactivate the mutant, arguing that binding is retained ( $\mathrm{Li}$ et al. 2005).

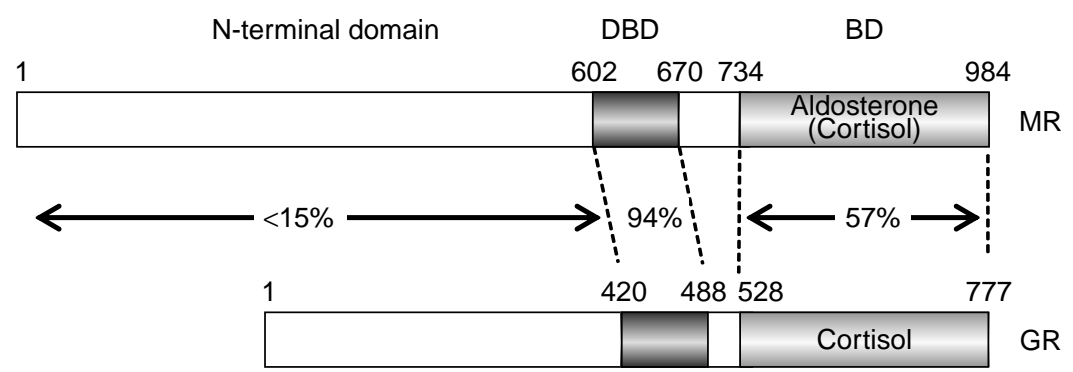

Figure 2 Schematic of the human mineralocorticoid receptor (MR) and the human glucocorticoid receptor (GR) with the percentage of amino acid identity between each domain; the figure has been adapted from Arriza et al. (1987). 
Studies by Hellal-Levy et al. (2000) show that the loop between helices 11 and 12 is also important for aldosterone-mediated transcriptional activity of MR. Functional analyses of the MR have revealed the importance of helices 11 and 12 in optimal positioning of helix 12 to form AF-2. Moreover, mutagenesis studies provide evidence that mutations in the loop positioning AF-2 can alter transcriptional activity of the MR, even when the mutant MR retains high affinity for both aldosterone and cortisol (Hellal-Levy et al. 2000, Rogerson \& Fuller 2003, Hultman et al. 2005).

Ligand-binding specificity is also demonstrated by the MR antagonist, spironolactone, in that it binds to both the MR and the AR, but binds poorly or not at all to the GR. The amino acid region $804-874$ in MR is also critical for the binding of spironolactone; the aforementioned S810L mutation turns spironolactone into an agonist. However, the antagonistic action of spironolactone on aldosterone-mediated MR transactivation depends critically on amino acid residues Ala-773 and Asn-770.

\section{Inter-domain interactions}

The major domains of the steroid receptors were originally thought to be 'modular' and generally functionally independent. However, studies in several steroid receptors provide clear evidence for a significant 'crosstalk' between domains, which can influence the activity of each domain as well as the activity of the receptor as a whole. An interaction between the NTD and the LBD (N/C-interaction) is very well characterized in the AR (He et al. 1999). It has also been described for the PR (Tetel et al. 1999) and ESR1 (Metivier et al. 2002) but is absent in the GR (Rogerson \& Fuller 2003). The liganddependent AR N/C-interaction contributes to AR dimerization and stabilizes ligand binding; its importance appears to vary with the gene promoter (Kemppainen et al. 1999). The AR N/C-interaction is direct and mediated through interactions between the FxxLF and WxxLF motifs in the N-terminus of the receptor, which upon ligand binding interact with and occupy a hydrophobic cleft created by helices 3, 4, 5 and 12 (He et al. 2002). Successful interaction of these two motifs is important for robust transcriptional activity. Recently, it has also been shown that the N/C-interaction is critical for AR-chromatin association in cells ( $\mathrm{Li}$ et al. 2005). The importance of this interaction is observed in cases of partial and complete androgen insensitivity in which ligand binding, nuclear localization and transactivation in vitro are essentially normal, but the interaction between the $\mathrm{N}$ - and the C-termini is lost. Recently, Schaufele et al. (2005) have demonstrated that the initial association between the $\mathrm{N}$ - and C-terminal regions in the AR is intramolecular but this is rapidly followed by ligand- induced dimerization in the nucleus which is characterized by an intermolecular association between AR. The FxxLF motif interacts with the AF-2 region such that it may serve to modulate the interactions of the LxxLL motif found in steroid receptor coactivators. In the ESR1, the $\mathrm{N} / \mathrm{C}$-interaction represses receptor activity in the absence of ligand (Metivier et al. 2002), and enhances coactivator binding in the presence of ligand (Metivier et al. 2000).

A ligand-dependent N/C-interaction in MR was first demonstrated by Rogerson \& Fuller (2003). Interestingly, despite mineralocorticoids and glucocorticoids being the physiological ligands for MR, the interaction was observed in response to aldosterone but only very weakly in the presence of cortisol. In fact, the aldosterone-mediated interaction is antagonized by cortisol. Further studies also demonstrated that the $\mathrm{N} / \mathrm{C}$-interaction in MR was specific for the N-terminus in that the substitution of the GR or AR N-terminus did not result in an interaction with the MR LBD. The N/Cinteraction of the MR is also repressed by the antagonists, spironolactone and eplerenone. The mechanism of the MR N/C-interaction differs from that of the AR in that MR N-terminus does not contain the FxxLF motif. The lack of interaction between the AR-NTD and the MR LBD further highlights the fundamental differences in the structural determinants of the N/C-interaction between the AR and the MR.

Based on evidence from recent studies, the difference in the abilities of aldosterone and cortisol to induce the $\mathrm{N} / \mathrm{C}$-interaction is potentially of enormous significance. First, the interaction may be the underlying mechanism that explains the tissue-specific effects of MR bound by cortisol. Secondly, it also identifies a subtle conformational difference in the aldosterone- and cortisolbound MR. However, the physiological significance of the $\mathrm{N} / \mathrm{C}$-interaction in MR is yet to be determined.

\section{Coregulators of MR}

The transcriptional activity of nuclear receptors is a function of their coregulator requirement and, or corepressor displacement (Xu et al. 2002). The MR contains two defined regions that interact with coactivators and mediate activation of transcription: AF-1 in the NTD and AF-2 in the LBD. The relative contribution of each is dependent on both the cell type and promoter context (Lim-Tio et al. 1997). The tissue-specific effects of cortisol/corticosterone at the MR are likely due to differential interaction with coregulators, perhaps through the N/C-interaction. A large number of coregulators have been identified (for example, p160 family, $\mathrm{CBP} / \mathrm{p} 300$, pCAF, $\mathrm{SWI} / \mathrm{SNF}$ ) that interact with both ligand-bound NRs, and also with other transcription factors (Alland $e t$ al. 1997, Glass \& Rosenfeld 2000, Stanley et al. 2003). 
Members of the p160 family of coactivators, steroid receptor coactivator-1 (SRC-1), SRC-2 and SRC-3, interact with the MR (Hultman et al. 2005) as does peroxisome proliferator $\gamma$-coactivator-1- $\alpha($ PGC- $1 \alpha)$ (Knutti \& Kralli 2001). The interaction of these coactivators is mainly through the AF-2 in the MR LBD. The crystal structure of the LBD of the steroid receptors, including the MR reveals that the $\mathrm{C}$-terminal helix adopts a specific conformation in the agonist bound state, which includes an activation surface (AF-2), to which the LxxLL motif can bind ( $\mathrm{Li}$ et al. 2005). The p160 coactivators and PGC- $1 \alpha$ interact with the MR, through one or more of these LxxLL motifs. When Hultman et al. (2005) and $\mathrm{Li}$ et al. (2005) examined the interaction of a large number of LxxLL motifs from known NR coactivators, with the MR LBD, the interaction was largely restricted to those from SRC1 and PGC- $1 \alpha$. This suggests that the conformation of the MR AF-2 region is subtly different from that of the other NR. It can also be inferred from these studies that, as with the AR, other motifs may be important in mediating the interaction of coactivators with the MR LBD; clearly, there is a need to identify MR-specific interacting molecules rather than focusing on the known NR coactivators as these previous studies have done.

Pascual-Le Tallec \& Lombes (2005) have reported that the elongation factor, ELL, is a highly selective coregulator of the MR which directly interacts with the NTD of the hMR and exerts AF-1b dependent coactivation. ELL behaves as a selective transcriptional regulator of MR in that, it represses GR transactivation and has no effect on the transcriptional activities of both the AR and the PR. ELL enhances both aldosterone- and cortisol-mediated MR transactivation. A coactivator complex that interacts with the MR AF-1 region was purified from HeLa cells, and found to contain CREB-binding protein $(\mathrm{CBP} / \mathrm{p} 300)$ and RNA helicase A (RHA; Kitagawa et al. 2002). Importantly, this complex interacts with the receptor via RHA in the presence of aldosterone but not cortisol. Given that the RHA complex interacts with the MR-NTD but in a ligand-dependent manner, the $\mathrm{N} / \mathrm{C}$-interaction may mediate or modulate this interaction. Such discrimination is likely to be significant in non-classical tissues. With the exception of this RHA complex, coactivators whose interaction with the MR depends on the nature of the ligand have yet to be identified.

To date, most studies have focused on renal and or/cardiovascular tissues for identifying MR-interacting coactivators (Pascual-Le Tallec \& Lombes 2005). Obradovic et al. (2004) screened a brain cDNA library to identify molecules interacting with the MR AF-1 region. A series of molecules homologous to the DAXX, FLASH and FAF1 genes, which are associated with apoptosis, which were able to modulate the transcriptional activity of the MR, were identified. FAF1 was MR specific, the others interacted with both the GR and MR.

Further studies seeking MR N-terminus interacting proteins identified the protein inhibitor of activated signal transducer and activator of transcription (PIAS) family of proteins (PIAS1, PIAS $_{\mathrm{x} \beta}$ and Ubc9 as MR coregulators. Both PIAS1 and PIAS $\mathrm{x}_{\mathrm{x} \beta}$ behave as small ubiquitin-related modifier-3 (SUMO-E3) ligases able to sumoylate MR both in vitroand in vivo (Metivier et al. 2000, Mihailidou et al. 2004); PIAS1 is a MR-specific corepressor which interacts with the NTD. Interestingly, repression of transcriptional activity of MR mediated by PIAS1 is both dependent and independent of the MR's sumoylation status (Pascual-Le Tallec et al. 2003). The SUMO-E2 activating enzyme, Ubc9, interacts with the MR-NTD/ DBD (1-670 amino acids) to potentiate aldosteronedependent MR transactivation (Yokota et al. 2007).

Overall, in contrast to other steroid receptors, the identification of MR coregulators and an understanding of structural determinants, within the MR, of these interactions, remain relatively limited.

\section{Transactivation}

The classical mechanism for the hormone-mediated MR signalling pathway is through regulation of transcription. As with all nuclear receptors, the activated receptor binds to response elements which act as enhancers in cis to influence the promoter activity of the target gene. To date, a very limited number of MR-induced genes and response elements which act at a primary transcriptional level have been identified. Genes identified as being regulated by aldosterone and fully characterized have primarily been expressed in epithelial tissues (Fuller \& Young 2005). They are generally also regulated by activation of the GR such that the response elements identified are GREs. So far there are no reports of identification of unique 'MREs'. Unique MREs are likely to be found in genes that are expressed in tissues which show a distinct MR versus GR response, which are generally non-epithelial tissues.

\section{Transrepression}

Transrepression represents a spectrum of functional molecular interactions that may occur either via DNA binding or through interference with other transcription factors via protein-protein interactions, independent of DNA binding by the receptor (Pascual \& Glass 2006). This is best described for the GR, where mutual transrepression of nuclear factor $\kappa \mathrm{B}(\mathrm{NF} \kappa \mathrm{B})$ or activator protein-1 (AP-1) signalling is fundamental to the anti-inflammatory response (De Bosscher et al. 
2003). In contrast to the GR, the MR does not interact with the AP-1 complex (Pearce \& Yamamoto 1993). Although, in vitro studies have described MR interactions with $\mathrm{NF} \kappa \mathrm{B}$ (Kolla \& Litwack 2000), this has not been confirmed in vivo and indeed, at least in the cardiovascular system, the MR is thought to be proinflammatory (Fuller \& Young 2005). However, this does not rule out interactions with other yet to be determined transcription factors where mutual transrepression may occur.

\section{Conclusions}

Although not generally as advanced as for the other steroid receptors, an understanding of structurefunction relationships in the MR is now emerging. Clinical studies such as the 'Randomised Aldactone Evaluation Study' (RALES) and the 'Eplerenone PostAcute Myocardial Infarction Heart Failure Efficacy and Survival Study' (EPHESUS) trials (Pitt 2004) in which MR antagonist therapy in patients with cardiac failure resulted in marked decreases in morbidity and mortality have given a major impetus to research on the MR. Similarly, recent studies have also identified a role for the MR in the pathophysiology of neurological disorders (DeRijk et al. 2006, Kuningas et al. 2007). The expanding knowledge of the structural basis of the molecular mechanisms of mineralocorticoid action may therefore provide a foundation for the development of novel therapeutic strategies. A key imperative is to define mechanisms by which tissue and ligand specificity of agonism and antagonism at the MR may be achieved. The differences observed at both functional and structural levels between the interactions of aldosterone and cortisol with the MR demonstrate the considerable plasticity present within the MR signal transduction pathway.

\section{Declaration of interest}

The authors declare that there is no conflict of interest that could be perceived as prejudicing the impartiality of the research reported.

\section{Funding}

JBP is supported by a Fred Boylan and Bill Burke Fellowship from Prince Henry's Institute of Medical Research and PJF is supported by a Senior Principal Research Fellowship from the National Health and Medical Research Council of Australia.

\section{Acknowledgements}

We thank Ms Sue Panckridge for her help in the preparation of this manuscript and Dr Morag Young for critically reading the manuscript.

\section{References}

Agarwal MK \& Mirshahi M 1999 General overview of mineralocorticoid hormone action. Pharmacology and Therapeutics 84 273-326.

Alland L, Muhle R, Hou H, Potes J Jr, Chin L \& Schreiber-Agus N 1997 Role for N-CoR and histone deacetylase in Sin3-mediated transcriptional repression. Nature 387 49-55.

Arai K, Tsigos C, Suzuki Y, Irony I, Karl M, Listwak S \& Chrousos GP 1994 Physiological and molecular aspects of mineralocorticoid receptor action in pseudohypoaldosteronism: a responsiveness test and therapy. Journal of Clinical Endocrinology and Metabolism 79 1019-1023.

Arriza JL, Weinberger C, Cerelli G, Glaser TM, Handelin BL, Housman DE \& Evans RM 1987 Cloning of human mineralocorticoid receptor complementary DNA: structural and functional kinship with the glucocorticoid receptor. Science 237 268-275.

Baker AR, McDonnell DP, Hughes M, Crisp TM, Mangelsdorf DJ, Haussler MR, Pike JW, Shine J \& O'Malley BW 1988 Cloning and expression of full-length cDNA encoding human vitamin D receptor. PNAS 85 3294-3298.

Baker ME, Chandsawangbhuwana C \& Ollikainen N 2007 Structural analysis of the evolution of steroid specificity in the mineralocorticoid and glucocorticoid receptors. BMC Evolutionary Biology 724.

Benbrook D \& Pfahl M 1987 A novel thyroid hormone receptor encoded by a cDNA clone from a human testis library. Science $\mathbf{2 3 8}$ 788-791.

Benbrook D, Lernhardt E \& Pfahl M 1988 A new retinoic acid receptor identified from a hepatocellular carcinoma. Nature 333 669-672.

Bledsoe RK, Montana VG, Stanley TB, Delves CJ, Apolito CJ, McKee DD, Consler TG, Parks DJ, Stewart EL, Willson TM et al. 2002 Crystal structure of the glucocorticoid receptor ligand binding domain reveals a novel mode of receptor dimerization and coactivator recognition. Cell 110 93-105.

Bledsoe RK, Madauss KP, Holt JA, Apolito CJ, Lambert MH, Pearce KH, Stanley TB, Stewart EL, Trump RP \& Willson TM 2005 A ligand mediated hydrogen bond network required for the activation of the mineralocorticoid receptor. Journal of Biological Chemistry 280 31283-31293.

De Bosscher K, Vanden Berghe W \& Haegeman G 2003 The interplay between the glucocorticoid receptor and nuclear factor-kappaB or activator protein-1: molecular mechanisms for gene repression. Endocrine Reviews 24 488-522.

Cachofeiro V, Miana M, de Las Heras N, Martín-Fernández B, Ballesteros S, Fernández-Tresguerres J \& Lahera V 2008 Aldosterone and the vascular system. Journal of Steroid Biochemistry and Molecular Biology 109 331-335.

Connell JMC, MacKenzie SM, Marie Freel E, Fraser R \& Davies E 2008 A lifetime of aldosterone excess: long-term consequences of altered regulation of aldosterone production for cardiovascular function. Endocrine Reviews 29 133-154.

DeRijk RH, Wust S, Meijer OC, Zennaro MC, Federenko IS, Hellhammer DH, Giacchetti G, Vreugdenhil E, Zitman F \& de Kloet KR 2006 A common polymorphism in the mineralocorticoid receptor modulates stress responsiveness. Journal of Clinical Endocrinology and Metabolism 91 5083-5089.

Fagart J, Huyet J, Pinon GM, Rochel M, Mayer C \& Rafestin-Oblin ME 2005 Cystal structure of a mutant mineralocorticoid receptor responsible for hypertension. Nature Structural and Molecular Biology $12554-555$.

Fan YS, Eddy RL \& Byers MG 1989 The human mineralocorticoid receptor gene (MLR) is located on chromosome 4 at q31.2. Cytogenetics and Cell Genetics $\mathbf{5 2}$ 83-84.

Farman N \& Rafestin-Oblin ME 2001 Multiple aspects of mineralocorticoid selectivity. American Journal of Physiology. Renal Physiology 280 F181-F192.

Ferrari P, Lovati E \& Frey FJ 2000 The role of the 11betahydroxysteroid dehydrogenase type 2 in human hypertension. Journal of Hypertension 18 241-248. 
Fuller PJ \& Young MJ 2005 Mechanisms of mineralocorticoid action. Hypertension 46 1227-1235.

Fuller PJ, Smith BJ \& Rogerson FM 2004 Cortisol resistance in the New World revisited. Trends in Endocrinology and Metabolism 15 296-299.

Funder JW 2006 Minireview: aldosterone and the cardiovascular system: genomic and nongenomic effects. Endocrinology 147 $5564-5567$.

Fuse H, Kitagawa H \& Kato S 2000 Characterization of transactivational property and coactivator mediation of rat mineralocorticoid receptor activation function-1 (AF-1). Molecular Endocrinology 14 889-899.

Geller DS, Farhi A \& Pinkerton N 2000 Activating mineralocorticoid receptor mutation in hypertension exacerbated by pregnancy. Science 289 119-123.

Glass CK \& Rosenfeld MG 2000 The coregulator exchange in transcriptional functions of nuclear receptors. Genes and Development $14121-141$.

Govindan MV \& Warriar N 1998 Reconstitution of the N-terminal transcription activation function of human mineralocorticoid receptor in a defective human glucocorticoid receptor. Journal of Biological Chemistry 273 24439-24447.

Gronemeyer H, Gustafsson JA \& Laudet V 2004 Principles for modulation of the nuclear receptor superfamily. Nature Reviews. Drug Discovery 3 950-964.

Grossmann C \& Gekle M 2007 Non-classical actions of the mineralocorticoid receptor: misuse of EGF receptors? Molecular and Cellular Endocrinology 277 6-12.

Grossmann C, Freudinger R, Mildenberger S, Husse B \& Gekle M 2008 $\mathrm{EF}$ domains are sufficient for nongenomic mineralocorticoid receptor actions. Journal of Biological Chemistry 283 7109-7116.

He B, Kemppainen JA, Voegel JJ, Gronemeyer H \& Wilson EM 1999 Activation function 2 in the human androgen receptor ligand binding domain mediates interdomain communication with the NH(2)-terminal domain. Journal of Biological Chemistry 274 37219-37225.

He B, Minges JT, Lee LW \& Wilson EM 2002 The FXXLF motif mediates androgen receptor-specific interactions with coregulators. Journal of Biological Chemistry 277 10226-10235.

Hellal-Levy C, Fagart J, Souque A, Wurtz J-M, Moras D \& Rafestin-Oblin M-E 2000 Crucial role of the H11-H12 loop in stabilizing the active conformation of the human mineralocorticoid receptor. Molecular Endocrinology 14 1210-1221.

Hultman ML, Krasnoperova NV, Li S, Du S, Xia C, Dietz JD, Lala DS, Welsch DJ \& Hu X 2005 The ligand-dependent interaction of mineralocorticoid receptor with coactivator and corepressor peptides suggests multiple activation mechanisms. Molecular Endocrinology 19 1460-1473.

Iniguez-Lluhi JA \& Pearce D 2000 A common motif within the negative regulatory regions of multiple factors inhibits their transcriptional synergy. Molecular and Cellular Biology 20 6040-6050.

Kemppainen JA, Langley E, Wong CI, Bobseine K, Kelce WR \& Wilson EM 1999 Distinguishing androgen receptor agonists and antagonists: distinct mechanisms of activation by medroxyprogesterone acetate and dihydrotestosterone. Molecular Endocrinology 13 $440-454$.

Kitagawa H, Yanagisawa J, Fuse H, Ogawa S, Yogiashi Y, Okuno A, Nagasawa H, Nakajima T, Matsumoto T \& Kato S 2002 Ligandselective potentiation of rat mineralocorticoid receptor activation function 1 by a CBP-containing histone acetyltransferase complex. Molecular and Cellular Biology 22 3698-3706.

De Kloet ER, Vreugdenhil E, Oitzl MS \& Joëls M 1998 Brain corticosteroid receptor balance in health and disease. Endocrine Reviews 19 269-301.

Knutti D \& Kralli A 2001 PGC-1, a versatile coactivator. Trends in Endocrinology and Metabolism 12 360-365.

Kolla V \& Litwack G 2000 Inhibition of mineralocorticoid-mediated transcription by NF-кB. Archives of Biochemistry and Biophysics 383 $38-45$.
Krust A, Kastner P, Petkovich M, Zelent A \& Chambon P 1989 A third human retinoic acid receptor, hRAR-gamma. PNAS 86 5310-5314.

Kuningas M, de Rijk RH, Westendorp RG, Jolles J, Slagboom PE \& van Heemst D 2007 Mental performance in old age dependent on cortisol and genetic variance in the mineralocorticoid and glucocorticoid receptors. Neuropsychopharmacology 32 1295-1301.

Kwak SP, Patel PD, Thompson RC, Akil H \& Watson SJ 1993 5'Heterogeneity of the mineralocorticoid receptor messenger ribonucleic acid: differential expression and regulation of splice variants within the rat hippocampus. Endocrinology 133 2344-2350.

Lavery DN \& McEwan IJ 2005 Structure and function of steroid receptor AF1 transactivation domains: induction of active conformations. Biochemical Journal 391 449-464.

Li Y, Suino K, Daugherty J \& Xu HE 2005 Structural and biochemical mechanisms for the specificity of hormone binding and coactivator assembly by mineralocorticoid receptor. Molecular Cell 19 367-380.

Lim-Tio SS, Keightley M-C \& Fuller PJ 1997 Determinants of specificity of transactivation by the mineralocorticoid or glucocorticoid receptor. Endocrinology 138 2537-2543.

Luisi BF, Xu WX, Otwinowski Z, Freedman LP, Yamamoto KR \& Sigler PB 1991 Crystallographic analysis of the interaction of the glucocorticoid receptor with DNA. Nature 352 497-505.

Mangelsdorf DJ, Thummel C, Beato M, Herrlich P, Schutz G, Umesono K, Blumberg B, Kastner P, Mark M \& Chambon P 1995 The nuclear receptor superfamily: the second decade. Cell $\mathbf{8 3}$ 835-839.

Matias PM, Donner P, Coelho R, Thomaz M, Peixoto C, Macedo S, Otto N, Joschko S, Scholz P \& Wegg A 2000 Structural evidence for ligand specificity in the binding domain of the human androgen receptor. Implications for pathogenic gene mutations. Journal of Biological Chemistry 275 26164-26171.

McDonnell DP, Mangelsdorf DJ, Pike JW, Haussler MR \& O'Malley BW 1987 Molecular cloning of complementary DNA encoding the avian receptor for vitamin D. Science 235 1214-1217.

McEwan I, Lavery D, Fischer K \& Watt K 2007 Natural disordered sequences in the amino terminal domain of nuclear receptors: lessons from the androgen and glucocorticoid receptors. Nuclear Receptor Signaling 5 e001.

Metivier R, Petit FG, Valotaire Y \& Pakdel F 2000 Function of $\mathrm{N}$-terminal transactivation domain of the estrogen receptor requires a potential alpha-helical structure and is negatively regulated by the A domain. Molecular Endocrinology 14 1849-1871.

Metivier R, Stark A, Flouriot G, Hubner MR, Brand H, Penot G, Manu D, Denger S, Reid G \& Kos M 2002 A dynamic structural model for estrogen receptor-alpha activation by ligands, emphasizing the role of interactions between distant A and E domains. Molecular Cell 10 1019-1032.

Mihailidou AS, Mardini M \& Funder JW 2004 Rapid, nongenomic effects of aldosterone in the heart mediated by epsilon protein kinase C. Endocrinology 145 773-780.

Morrison N, Harrap SB \& Arriza JL 1990 Regional chromosomal assignment of the human mineralocorticoid receptor gene to 4q31.1. Human Genetics 85 130-132.

Obradovic D, Tirard M, Nmethy Zs, Hirsch O, Gronemeyer H \& Almeida OFX 2004 DAXX, FLASH, and FAF-1 modulate mineralocorticoid and glucocorticoid receptor-mediated transcription in hippocampal cells-toward a basis for the opposite actions elicited by two nuclear receptors? Molecular Pharmacology 65 761-769.

Ortlund EA, Bridgham JT, Redinbo MR \& Thornton JW 2007 Crystal structure of an ancient protein: evolution by conformational epistasis. Science 317 1544-1548.

Pascual G \& Glass CK 2006 Nuclear receptors versus inflammation: mechanisms of transrepression. Trends in Endocrinology and Metabolism 17 321-327.

Pascual-Le Tallec L \& Lombes M 2005 The mineralocorticoid receptor: a journey exploring its diversity and specificity of action. Molecular Endocrinology 19 2211-2221. 
Pascual-Le Tallec L, Kirsh O, Lecomte MC, Viengchareun S, Zennaro MC, Dejean A \& Lombes M 2003 Protein inhibitor of activated signal transducer and activator of transcription 1 interacts with the $\mathrm{N}$-terminal domain of mineralocorticoid receptor and represses its transcriptional activity: implication of small ubiquitin-related modifier 1 modification. Molecular Endocrinology 17 2529-2542.

Pearce D \& Yamamoto KR 1993 Mineralocorticoid and glucocorticoid receptor activities distinguished by nonreceptor factors at a composite response element. Science 259 1161-1165.

Petkovich M, Brand NJ, Krust A \& Chambon P 1987 A human retinoic acid receptor which belongs to the family of nuclear receptors. Nature 330 444-450.

Pitt B 2004 Effect of aldosterone blockade in patients with systolic left ventricular dysfunction: implications of the RALES and EPHESUS studies. Molecular and Cellular Endocrinology 217 53-58.

Rafestin-Oblin ME, Souque A, Bocchi B, Pinon G, Fagart J \& Vandewalle A 2003 The severe form of hypertension caused by the activating $\mathrm{S} 810 \mathrm{~L}$ mutation in the mineralocorticoid receptor is cortisone related. Endocrinology 144 528-533.

Robin-Jagerschmidt C, Wurtz JM, Guillot B, Gofflo D, Benhamou B, Vergezac A, Ossart C, Moras D \& Philibert D 2000 Residues in the ligand binding domain that confer progestin or glucocorticoid specificity and modulate the receptor transactivation capacity. Molecular Endocrinology 14 1028-1037.

Rogerson FM \& Fuller PJ 2003 Interdomain interactions in the mineralocorticoid receptor. Molecular and Cellular Endocrinology 200 $45-55$.

Rogerson FM, Dimopoulos N, Sluka P, Chu S, Curtis AJ \& Fuller PJ 1999 Structural determinants of aldosterone binding selectivity in the mineralocorticoid receptor. Journal of Biological Chemistry $\mathbf{2 7 4}$ 36305-36311.

Rupprecht R, Arriza JL, Spengler D, Reul JM, Evans RM, Holsboer F \& Damm K 1993 Transactivation and synergistic properties of the mineralocorticoid receptor: relationship to the glucocorticoid receptor. Molecular Endocrinology 7 597-603.

Schaufele F, Carbonell X, Guerbadot M, Borngraeber S, Chapman MS, Ma AAK, Miner JN \& Diamond MI 2005 The structural basis of androgen receptor activation: intramolecular and intermolecular amino-carboxy interactions. PNAS 102 9802-9807.

Shiau AK, Barstad D, Loria PM, Cheng L, Kushner PJ, Agard DA \& Greene GL 1998 The structural basis of estrogen receptor/coactivator recognition and the antagonism of this interaction by tamoxifen. Cell 95 927-937.

Stanley TB, Leesnitzer LM, Montana VG, Galardi CM, Lambert MH, Holt JA, Xu HE, Moore LB, Blanchard SG \& Stimmel JB 2003 Subtype specific effects of peroxisome proliferator-activated receptor ligands on corepressor affinity. Biochemistry 42 9278-9287.

Stewart PM \& Mason JI 1995 Cortisol to cortisone: glucocorticoid to mineralocorticoid. Steroids 60 143-146.

Struthers AD 2004 Aldosterone in heart failure: pathophysiology and treatment. Current Heart Failure Reports 1 171-175.
Sturm A, Bury N, Dengreville L, Fagart J, Flouriot G, Rafestin-Oblin ME \& Prunet P 2005 11-Deoxycorticosterone is a potent agonist of the rainbow trout (Oncorhynchus mykiss) mineralocorticoid receptor. Endocrinology 146 47-55.

Takeda Y, Yoneda T, Demura M, Miyamori I \& Mabuchi H 2000 Cardiac aldosterone production in genetically hypertensive rats. Hypertension 36 495-500.

Tetel MJ, Giangrande PH, Leonhardt SA, McDonnell DP \& Edwards DP 1999 Hormone-dependent interaction between the amino- and carboxyl-terminal domains of progesterone receptor in vitro and in vivo. Molecular Endocrinology 13 910-924.

Viengchareun S, Le Menuet D, Martinerie L, Munier M, Pascual-Le Tallec L \& Lombs M 2007 The mineralocorticoid receptor: insights into its molecular and (patho) physiological biology. Nuclear Receptor Signaling 5 e012.

Vivat V, Gofflo D, Garcia T, Wurtz JM, Bourguet W, Philibert D \& Gronemeyer H 1997 Sequences in the ligand-binding domains of the human androgen and progesterone receptors which determine their distinct ligand identities. Journal of Molecular Endocrinology 18 147-160.

Wehling M, Eisen C \& Christ M 1992 Aldosterone-specific membrane receptors and rapid non-genomic actions of mineralocorticoids. Molecular and Cellular Endocrinology 90 C5-C9.

Weinberger C, Hollenberg SM, Ong ES, Harmon JM, Brower ST, Cidlowski J, Thompson EB, Rosenfeld MG \& Evans RM 1985 Identification of human glucocorticoid receptor complementary DNA clones by epitope selection. Science 228 740-743.

White PC, Mune T \& Agarwal AK 1997 11ß-Hydroxysteroid dehydrogenase and the syndrome of apparent mineralocorticoid excess. Endocrine Reviews 18 135-156.

Williams SP \& Sigler PB 1998 Atomic structure of progesterone complexed with its receptor. Nature 393 392-396.

Xu HE, Stanley TB, Montana VG, Lambert MH, Shearer BG, Cobb JE, McKee DD, Galardi CM, Plunket KD, Nolte RT et al. 2002 Structural basis for antagonist-mediated recruitment of nuclear co-repressors by PPARalpha. Nature 415 813-817.

Yokota K, Shibata H, Kurihara I, Kobayashi S, Suda N, Murai-Takeda A, Saito I, Kitagawa H, Kato S \& Saruta T 2007 Coactivation of the N-terminal transactivation of mineralocorticoid receptor by Ubc 9 . Journal of Biological Chemistry 282 1998-2010.

Zennaro M-C, Keightley M-C, Kotelevtsev Y, Conway GS, Soubrier F \& Fuller PJ 1995 Human mineralocorticoid receptor genomic structure and identification of expressed isoforms. Journal of Biological Chemistry 270 21016-21020.

Zhang J, Tsai FTF \& Geller DS 2006 Differential interaction of RU486 with the progesterone and glucocorticoid receptors. Journal of Molecular Endocrinology 37 163-173.

Received in final form 3 September 2008

Accepted 19 September 2008

Made available online as an Accepted Preprint

19 September 2008 